\title{
Social Support and Mortality in Community- Dwelling Chinese Older Adults: The Mediating Role of Frailty
}

This article was published in the following Dove Press journal: Risk Management and Healthcare Policy

\author{
Lijun Fan ${ }^{1,2}$ \\ Shiyuan Wang ${ }^{1,3}$ \\ Hui Xue ${ }^{1,3}$ \\ Yue Ding ${ }^{1,2}$ \\ Jingwen Wang ${ }^{1,2}$ \\ Yong Tian ${ }^{1,2}$ \\ Wei Du (iD) ${ }^{1,3}$
}

\begin{abstract}
'Key Laboratory of Environmental Medicine Engineering of Ministry of Education, School of Public Health, Southeast University, Nanjing, People's Republic of China; ${ }^{2}$ Department of Medical Insurance, School of Public Health, Southeast University, Nanjing, People's Republic of China; ${ }^{3}$ Department of Epidemiology and Biostatistics, School of Public Health, Southeast University, Nanjing, People's Republic of China
\end{abstract}

Purpose: Population ageing is posing an unprecedented challenge globally, necessitating a better understanding of modifiable factors and underlying pathways that could contribute to health and longevity in older age. We thus aim to investigate how the modifiable social support (and its various sources) is related to mortality among older adults, as well as whether and to what extent geriatric frailty plays a role in mediating the relationship.

Methods: We included 11,934 community-dwelling adults $(\geq 65)$ from four waves of the Chinese Longitudinal Healthy Longevity Survey (2008-2018). Frailty was constructed by 44 health deficits, following a validated frailty index scale. Social support was measured using a sum score of three dimensions (family support, social service and social security) with 22 items. The outcome was all-cause mortality. Multivariate logistic or linear regression models were employed when appropriate to assess the associations among social support, frailty and mortality. Mediation analysis was applied to examine the role of frailty underlying the pathway between social support and mortality risk.

Results: A higher sum score of social support at baseline reduced mortality risk during the 10-year follow-up period ( $\mathrm{AOR}=0.947,95 \% \mathrm{CI}=0.917 \sim 0.977$ ). Amongst three sources of social support, family support and social security availability showed significantly protective effect against mortality, while social service revealed only non-significant effect. A higher level in the overall social support $(\beta=-0.066,95 \% \mathrm{CI}=-0.113 \sim-0.020)$ or family support $(\beta=$ $-0.121,95 \% \mathrm{CI}=-0.202 \sim-0.039)$ was also significantly associated with decreased frailty. Meanwhile, frailty partially mediated the relationship of mortality with the overall social support and family support, where the proportion of mediation equaled to $17.1 \%$ and $20.5 \%$, respectively.

Conclusion: Social support could be associated with reduced risks for frailty and mortality, and such protective influences are especially manifested in its family support component among Chinese older adults. Frailty functions as potential mediator underlying the association of mortality with social support and family support. Our findings indicate the importance of social support as an integral part of geriatric care and underline the potential benefits of frailty assessment and intervention.

Keywords: social support, frailty, mortality, older adults, mediation, China

\section{Introduction}

China is currently experiencing rapid population aging, accompanied by reduction in traditional family size and transition in dominant family structure from multigenerational households to nuclear families. ${ }^{1}$ Such a situation brings about portentous challenges to the society in maintaining autonomy and well-being of older
Department of Epidemiology and

Biostatistics, School of Public Health,

Southeast University, No. 87 Dingjiaqiao,

Nanjing, 210009, People's Republic of

China

Email duwei@seu.edu.cn
Risk Management and Healthcare Policy 2021:14 I583-1593

your manuscript

DovePress f in $\mathbf{D}$ 
persons, and underscores the urgency to examine social support as a potentially important approach for improving healthy aging. ${ }^{2,3}$

Social support is a multidimensional concept that generally includes the support accessible to an individual through social ties to other individuals, groups, and the larger community. ${ }^{4}$ The protective effect of social support against mortality in older adults has been commonly observed in numerous empirical studies. ${ }^{5-8}$ Nevertheless, social support is a rather complex indicator including support from various sources in and outside the family (mainly families, communities and social institutions), ${ }^{9,10}$ wherein different types of social support are expected to introduce distinct impact per se. For instance, China as a traditionally family-centered country may rely substantially on family-based support, while western countries with relatively abundant social welfare may be more likely to count on public support. ${ }^{10-12}$ However, to date, there are few studies distinguishing different sources of social support. Existing evidence often used a composite social support index ${ }^{6-8}$ or assessed only one particular type without reciprocal comparisons. ${ }^{13}$ It is thus warranted to further investigate how various sources of social support could impact on health outcomes in Chinese context.

Although plenty of evidence has documented the important role of social support in reducing mortality in later life, the possible mechanism remains to be elucidated. Frailty, defined as a multidimensional measure of vulnerability assessing the generalized decline of individuals and a good proxy for biological aging, ${ }^{14,15}$ has been increasingly recognized in gerontological research and literature as a strong predictor for detrimental health outcomes including mortality. ${ }^{16-20}$ Moreover, a growing body of research proposed that frailty syndrome could be aggravated due to lack of social support, even though such evidence was currently concentrated in developed countries. For instance, presence of social support was previously found to be linked to reduced frailty in Germany, $^{21}$ Austrian, ${ }^{22}$ and Korean $^{23}$ populations. The aforementioned evidence shed light on the possibility of frailty involved in the pathway between social support and mortality, and it is thus of interest to test whether frailty plays a mediating role.

Therefore, the scope of this study is to analyze how social support is related to frailty and survival among Chinese older adults using large-scale nationwide data, with additional focus on disentangling specific impact from various sources of social support in the Asian context. We further test the mediating role of frailty in the process whereby social support is associated with morality.

\section{Materials and Methods Data and Sample}

This study utilized four waves of data across a span of 10 years (2008-2018) from the Chinese Longitudinal Healthy Longevity Survey (CLHLS). Briefly, CLHLS is an ongoing nationwide cohort of older adults in China aimed at understanding the determinants for health longevity. CLHLS used structured questionnaires to collect individual-level data concerning personal sociodemographic characteristics, social and behavioral risk factors, and a myriad of physical, psychological and social-related conditions. The participants were sampled following a stratified probability sampling approach from a randomly selected half of the counties and cities in 22 out of China's 31 provinces. Further details of study objectives and procedures of CLHLS have been described elsewhere. $^{24,25}$ The baseline interview (2008) of CLHLS enrolled 16,954 participants, and the analytic sample of our study featured 11,934 community-dwelling Chinese older adults after excluding individuals who were lost to follow-up, aged below 65 years, or had reported incomplete data on the independent and dependent variables of interest. Figure 1 illustrates the flowchart of study sample. Ethical approval for the CLHLS survey was granted from the Research Ethics Committees of Duke University and Peking University. All participants provided written informed consent.

\section{Measures}

\section{Social Support}

Social support in this study was measured with three dimensions: family support, social service (community support) and social security (public support), which was consistent with previous literature. ${ }^{9-11}$ The first dimension (family support) referred to the existence or availability of emotional and instrumental support from family, which was evaluated by six items: marital status (whether participants were currently married and living with spouse), coresidence arrangement (whether participants were living with household members), frequent contacts with family (whether family members frequently talked to participants), frequent visits from family (whether family members frequently visited participants), financial support 


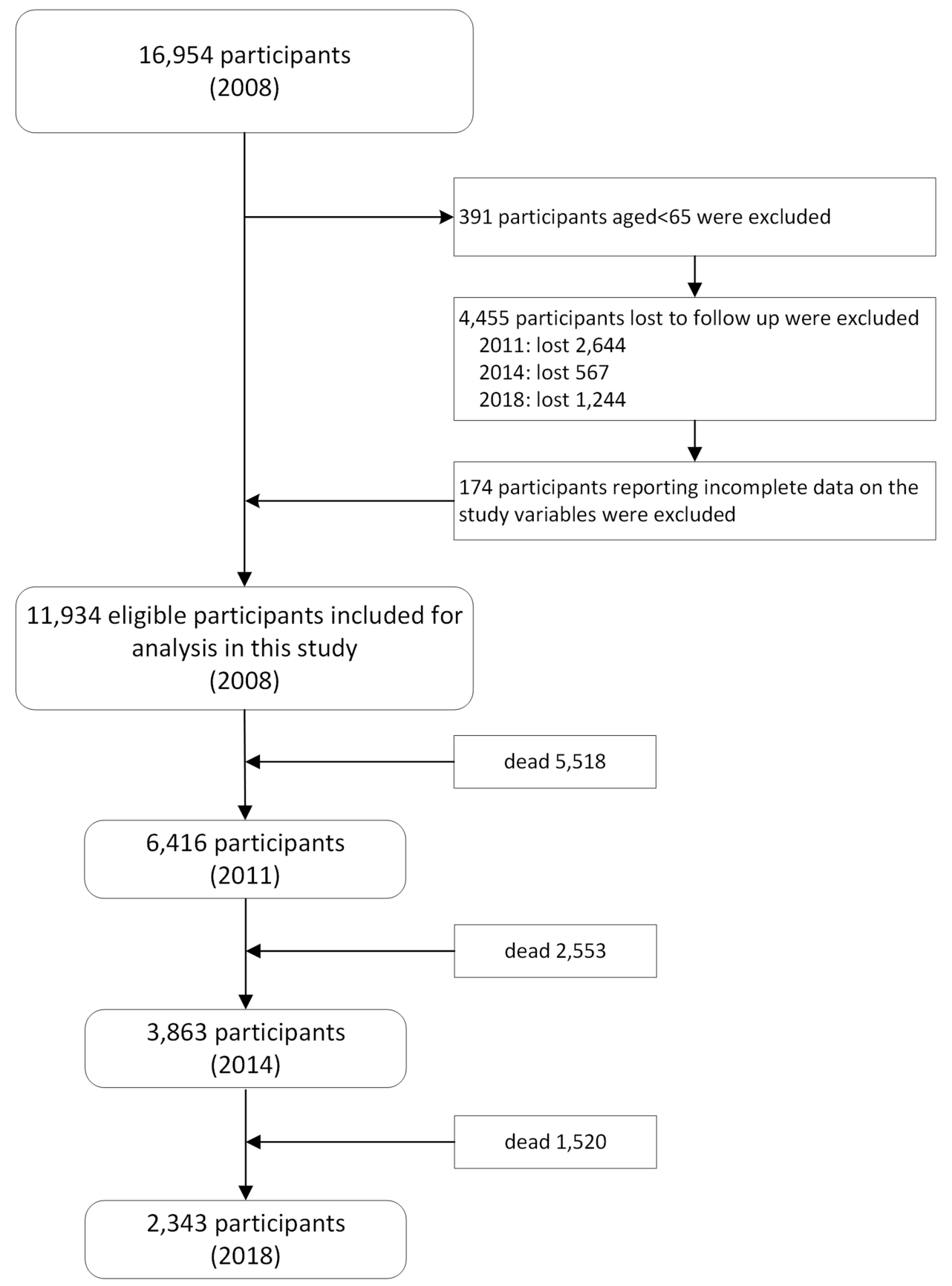

Figure I A flowchart of the study sample from 2008 to 2018 .

receipt (whether participants received money from children), and sick care (whether family members provided care to participants when they were in sick). The second and third dimensions belonged to the provision of support through real or perceived existence of resources outside the family. The availability of social services was assessed by asking whether a series of social services was available in the community, including personal daily care services, house call physicians, psychological consulting, daily shopping, social and recreation activities, legal aid, healthcare education, and mediation of neighborhood disputes (eight items). The availability of social security was assessed by asking if participants were enrolled in a range of social insurances, including retirement pension, public old-age insurance, private old-age insurance, public free medical services, cooperative medical scheme, basic medical insurance, severe disease insurance, and life insurance (eight items). For the above total of 22 items, each 
variable was dichotomized with values of ' 1 ' representing the presence of a social deficit and ' 0 ' denoting the absence. A composite score of social support was then constructed by summing up all values of the 22 selfreported domains, yielding a theoretical range of $0 \sim 22$. A higher score indicates better social support. Social support was measured at baseline. Cronbach's $\alpha$ in this study was 0.882 , indicating good reliability.

\section{Frailty}

Frailty was operationalized following an adapted version of Rockwood's frailty index scale, which had been previously validated. ${ }^{26,27}$ Using a cumulative deficit approach, a frailty score was generated based upon 44 health deficits covering activities of daily living, chronic disease conditions, hearing or vision impairment, cognitive and psychological functions, and other health-related dimensions. These selected deficit items were similar to those used in other studies. ${ }^{28,29}$ Each deficit was treated as a dichotomous or ordinal variable, measured on a scale between 0 and 1 to denote the increasing severity of health deficits. For example, "hypertension" deficit was coded as " 0 " if the participant was absent from this deficit and " 1 " otherwise; "dressing on one's own" deficit was coded as " 0 " if the participant could finish this task without assistance, " 0.5 " if needing partial assistance and " 1 " if requiring full assistance. We then quantified the overall level of frailty for a given participant by summing up all values of the 44 deficits, using the baseline data. Participants who had missing value for any deficit were considered missing in frailty measurement. The frailty level ranges from 0 to 44 , with an increasing score indicating a higher level of frailty. To improve readability of coefficients in regression models, we kept using the $0 \sim 44$ range for total frailty score instead of the $0 \sim 1$ range for frailty index (which was equaled to the total frailty score divided by 44). Cronbach's $\alpha$ for the frailty scale was 0.908 in this study, which implied high internal consistency.

\section{Mortality}

The outcome of interest was all-cause mortality over ten years, which was coded as a binary status (death or survival). The outcome was measured by confirming the participants' survival status at each follow-up wave, through interviews with close family members of the deceased. Although death registration data would most accurately reflect the deceased's information including date of death, this information was not available hence the current approach was deemed the most feasible way of obtaining data that our study requested.

\section{Covariates}

The following covariates were included in multivariate analyses: age, gender, residence (rural, urban), education attainment $(<1$ year, 1-6 years, $>6$ years), main occupation (white-collar or not), BMI $\left(<18.5 \mathrm{~kg} / \mathrm{m}^{2}, 18.5-24 \mathrm{~kg} / \mathrm{m}^{2}\right.$, $\geq 24 \mathrm{~kg} / \mathrm{m}^{2}$ ), smoking (never, former smoker, current smoker) and drinking (never, former drinker, current drinker). These variables were selected because they were significant at $p<0.1$ in univariate analyses or widely reported in previous literature.

\section{Statistical Analysis}

Means and standard deviations (SD) were used to describe continuous variables, and absolute frequencies and proportions were applied to summarize categorical variables. Bivariate analyses were conducted using $t$-tests or $\chi^{2}$ tests (whichever appropriate) to compare the sociodemographic differences according to mortality status. The associations of social support with frailty and mortality were examined by multivariate logistic regression (when the outcome variable is binary) or linear regression models (when the outcome variable is continuous) as appropriate. Two models were conducted to illustrate possible confounding: a crude model without adjustment for any confounder; and an adjusted model controlling for age, gender, residence, education attainment, main occupation, BMI, smoking and drinking.

The simple mediation model (Figure 2) was conducted to further determine whether and to what extent frailty mediated the association between social support and mortality. According to Baron and Kenny, ${ }^{30}$ a mediating model was constructed using hierarchical regression analyses after adjusting for all aforementioned covariates: in step 1 , the outcome variable ( $\mathrm{Y}$, frailty) was regressed on the independent variable (X, social support or its three sources); in step 2, the presumed mediator (M, frailty) was regressed on the independent variable (X, social support or its sources); and in step 3, the presumed mediator (M, frailty) was added to the model in step 1. Afterwards, the Bootstrapping method with 5000 resamples was applied to test the mediating effect of frailty using the PROCESS macro in SPSS. ${ }^{31} \mathrm{We}$ assessed the biascorrected bootstrap confidence intervals (CI) of indirect effects, which were considered significant if the upper and lower bound of the $95 \%$ CI did not straddle zero. 


\section{A}

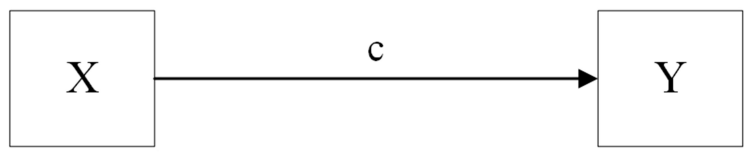

$$
\mathrm{Y}=\mathrm{cX}+\mathrm{e}_{1}
$$

B

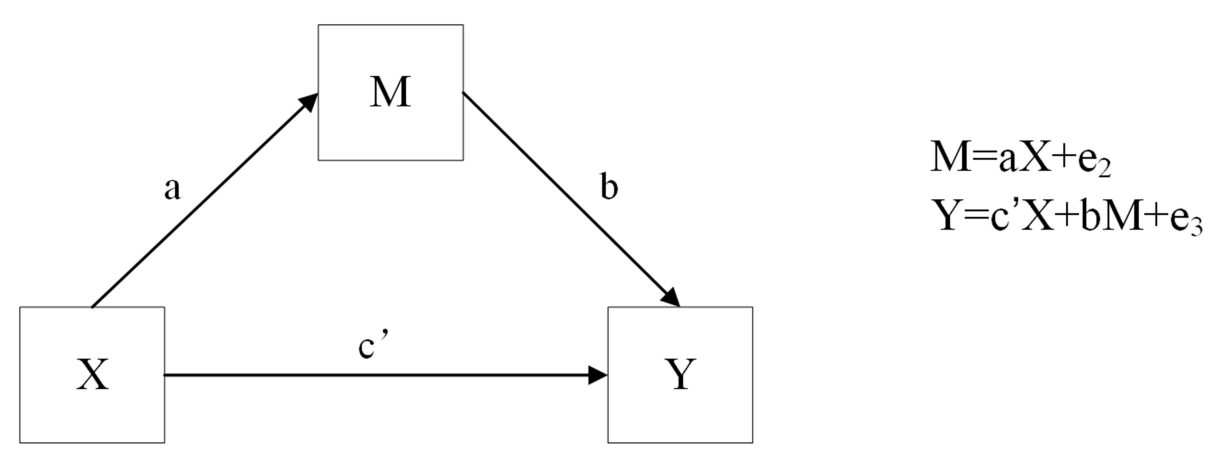

Figure 2 A simple mediation model in path diagram form. The upper figure $(\mathbf{A})$ : total effect of $X$ on $Y$; the lower figure (B): direct and indirect effect of $X$ on $Y$.

The proportion of mediation (interpreted as the proportion of the effect of $\mathrm{X}$ on $\mathrm{Y}$ that was mediated by $\mathrm{M}$ ) was then calculated as follows: ${ }^{32}$

For dichotomous outcome: proportion of mediation $=\frac{\mathrm{OR}^{\mathrm{DE}} \times\left(\mathrm{OR}^{\mathrm{IE}}-1\right)}{\mathrm{OR}^{\mathrm{DE}} \times \mathrm{OR}^{\mathrm{IE}}-1}$

In this equation: $\mathrm{OR}^{\mathrm{DE}}$ was the odds ratio of the partial coefficient of $\mathrm{X}$ on $\mathrm{Y}$ while holding $\mathrm{M}$ constant, and $\mathrm{OR}^{\mathrm{IE}}$ was the exponent of the product by the partial coefficient of $\mathrm{M}$ on $\mathrm{Y}$ while holding $\mathrm{X}$ constant and the partial coefficient of $\mathrm{X}$ on $\mathrm{M}$.

All analyses were conducted with Stata version 16.0 (Stata Corp, College Station, TX) and SPSS version 22.0 (SPSS Inc., Chicago, IL). A two-tailed $p$-value below 0.05 was considered statistically significant.

\section{Results}

\section{Sample Characteristics}

A total of 11,934 participants (aged $88.1 \pm 11.2$ years, ranged from 65 to 116 years, $42.2 \%$ male) were enrolled in this study at baseline. Out of these participants, 9591 (80.4\%) were dead during the 9-year follow-up period. The socio-demographic characteristics of participants are shown in Table 1. Results from univariate analysis indicated that individuals were more likely to survive if they were younger, male, more educated, white-collar, current smoker or drinker, or had normal BMI. Survived people appeared to have lower frailty score $(5.85 \pm 2.76$ in survivors versus $10.75 \pm 5.39$ in deceased people), and they received higher level of social support $(5.90 \pm 1.97$ in survivors versus $5.14 \pm 1.80$ in deceased people) or its three components (all $p<0.05$ ).

\section{Association of Social Support with Frailty and Mortality}

Table 2 presents results on the relationship between social support and mortality in community-dwelling older adults. In the crude model without adjustment for any confounder, results revealed that older adults with higher level of social support or its three different sources were consistently associated with a lower incidence of mortality (all $p<0.05)$. This remained the case for the total social support score $(\mathrm{AOR}=0.947,95 \% \mathrm{CI}=0.917 \sim 0.977$ ), family support (AOR $=0.918,95 \% \mathrm{CI}=0.865 \sim 0.973)$ and social security availability $(\mathrm{AOR}=0.869,95 \% \mathrm{CI}=0.803 \sim 0.940)$, when models were adjusted for potential confounders including age, gender, residence, education attainment, main occupation, BMI, smoking and drinking. However, the protective effect of social service against mortality was no longer significant when additional adjustment was made (AOR $=0.988,95 \%$ CI $=0.946 \sim 1.033)$. 
Table I Baseline Sample Characteristics of Community-Dwelling Chinese Older Adults in the CLHLS

\begin{tabular}{|c|c|c|c|c|}
\hline \multirow[t]{2}{*}{ Characteristics } & \multirow[t]{2}{*}{ Total $^{a}(n=\mid I, 934)$} & \multicolumn{2}{|c|}{ Mortality ${ }^{\mathbf{b}}$} & \multirow[t]{2}{*}{$p$ value } \\
\hline & & Survived & Died & \\
\hline Age, year & & & & $<0.001$ \\
\hline $65-75$ & $1883(15.78)$ & $1259(53.73)$ & $624(6.5 I)$ & \\
\hline $75-85$ & $2359(19.77)$ & $763(32.57)$ & $1596(16.64)$ & \\
\hline $85-95$ & $3975(33.31)$ & $260(11.10)$ & $3715(38.73)$ & \\
\hline$>95$ & $3717(31.15)$ & $61(2.60)$ & $3656(38.12)$ & \\
\hline Gender & & & & $<0.001$ \\
\hline Male & $5036(42.20)$ & $1077(45.97)$ & $3959(4 I .28)$ & \\
\hline Female & $6898(57.80)$ & $1266(54.03)$ & $5632(58.72)$ & \\
\hline Residence & & & & 0.110 \\
\hline Urban & $1656(13.88)$ & $30 I(12.85)$ & $1355(14.13)$ & \\
\hline Rural & $10,278(86.12)$ & $2042(87.15)$ & $8236(85.87)$ & \\
\hline Education attainment, year & & & & $<0.001$ \\
\hline$<1$ & $7836(65.66)$ & II $48(49.00)$ & $6688(69.73)$ & \\
\hline $1-6$ & $3153(26.42)$ & $882(37.64)$ & 227 I (23.68) & \\
\hline$>6$ & $945(7.92)$ & $313(13.36)$ & $632(6.59)$ & \\
\hline Main occupation & & & & $<0.001$ \\
\hline White-collar & 671 (5.62) & $186(7.94)$ & $485(5.06)$ & \\
\hline Others & II,263 (94.38) & $2157(92.06)$ & $9106(94.94)$ & \\
\hline BMI, $\mathrm{kg} / \mathrm{m}^{2}$ & & & & $<0.001$ \\
\hline$<18.5$ & $4100(34.36)$ & $515(21.98)$ & $3585(37.38)$ & \\
\hline $18.5-24$ & $7638(64.00)$ & $1824(77.85)$ & $5814(60.62)$ & \\
\hline$\geq 24$ & $196(1.64)$ & $4(0.17)$ & $192(2.00)$ & \\
\hline Smoking & & & & $<0.001$ \\
\hline Never & $7952(66.63)$ & $1516(64.70)$ & $6436(67.10)$ & \\
\hline Former & $1904(15.95)$ & $313(13.36)$ & I59I (16.59) & \\
\hline Current & $2078(\mid 7.4 I)$ & $514(21.94)$ & $1564(|6.3|)$ & \\
\hline Drinking & & & & $<0.001$ \\
\hline Never & $8172(68.48)$ & $1549(66.11)$ & $6623(69.05)$ & \\
\hline Former & $1666(13.96)$ & $294(12.55)$ & $1372(|4.3|)$ & \\
\hline Current & $2096(17.56)$ & $500(21.34)$ & $1596(16.64)$ & \\
\hline Social support (total score), Mean \pm SD & $5.28 \pm 1.86$ & $5.90 \pm 1.97$ & $5.14 \pm 1.80$ & $<0.001$ \\
\hline Social support (components), Mean \pm SD & & & & \\
\hline Family support & $3.79 \pm 1.04$ & $4.21 \pm 1.01$ & $3.69 \pm 1.02$ & $<0.001$ \\
\hline Social service & $0.56 \pm 1.25$ & $0.61 \pm 1.32$ & $0.55 \pm 1.23$ & 0.04 \\
\hline Social security & $0.94 \pm 0.76$ & $1.08 \pm 0.84$ & $0.90 \pm 0.74$ & $<0.001$ \\
\hline Frailty, Mean \pm SD & $9.78 \pm 5.35$ & $5.85 \pm 2.76$ & $10.75 \pm 5.39$ & $<0.001$ \\
\hline
\end{tabular}

Notes: ${ }^{a}$ Data are expressed as counts (percentages) except when specified otherwise. ${ }^{b} \chi^{2}$ tests were used for categorical variables and $t$ tests were used for continuous variables.

Table 3 depicts the association of social support (and its three components) with frailty. An increasing level of the overall social support, family support or social security support was significantly associated with a lower total score for frailty (all $p<0.05$ ), while the increased social service support showed only non-significant protective effect towards frailty $(p>0.05)$. After additionally controlling for aforementioned confounders, the significant protective effective from overall social support (adjusted $\beta=-0.066,95 \% \mathrm{CI}=-0.113 \sim-0.020$ ) and family support 
Table 2 Association of Social Support (and Its Three Components) with Mortality

\begin{tabular}{|c|c|c|}
\hline \multirow[t]{2}{*}{ Variable } & \multicolumn{2}{|c|}{ Mortality at Follow-Up $(n=I I, 934)$} \\
\hline & Crude $M o d e l^{a}$, OR $(95 \% \mathrm{Cl})$ & Adjusted Model $^{\mathrm{b}}$, OR $(95 \% \mathrm{Cl})$ \\
\hline Social support (total score) & $0.815(0.797,0.835)^{* * *}$ & $0.947(0.917,0.977)^{* *}$ \\
\hline Social support (components) & & \\
\hline Family support & $0.543(0.513,0.574)^{* * *}$ & $0.918(0.865,0.973)^{* *}$ \\
\hline Social service & $0.964(0.931,0.998)^{*}$ & $0.988(0.946,1.033)$ \\
\hline Social security & $0.755(0.715,0.798)^{* * *}$ & $0.869(0.803,0.940)^{* * *}$ \\
\hline
\end{tabular}

Notes: a Crude model was unadjusted for any confounding variables. ${ }^{b}$ Adjusted model was adjusted for confounders including age, gender, residence, education attainment, main occupation, BMI, smoking and drinking. ${ }^{*} p<0.05$, ${ }^{* *} p<0.01$, ${ }^{* * *} p<0.001$.

Abbreviations: $\mathrm{OR}$, odds ratio; $\mathrm{Cl}$, confidence interval.

Table 3 Association of Social Support (and Its Three Components) with Frailty

\begin{tabular}{|l|c|c|}
\hline \multirow{2}{*}{ Variable } & \multicolumn{2}{|c|}{ Frailty (n=I I,934) } \\
\cline { 2 - 3 } & Crude Model $^{\mathbf{a}}, \boldsymbol{\beta} \mathbf{~ ( 9 5 \% ~ C l )}$ & Adjusted Model $^{\mathbf{b}}, \boldsymbol{\beta}$ (95\% Cl) \\
\hline Social support (total score) & $-0.438(-0.489,-0.387)^{* * *}$ & $-0.066(-0.113,-0.020)^{* *}$ \\
\hline Social support (components) & & $-0.121(-0.202,-0.039)^{* *}$ \\
Family support & $-1.016(-1.107,-0.926)^{* * *}$ & $-0.018(-0.083,0.047)$ \\
Social service & $-0.050(-0.127,0.027)$ & $-0.107(-0.220,0.007)$ \\
Social security & $-0.578(-0.703,-0.452)^{* * *}$ & \\
\hline
\end{tabular}

Notes: ${ }^{a}$ Crude model was unadjusted for any confounding variables. ${ }^{\mathrm{b}}$ Adjusted model was adjusted for confounders including age, gender, residence, education attainment, main occupation, BMI, smoking and drinking. $* * p<0.01$, $* * * p<0.00 \mathrm{I}$.

Abbreviation: $\mathrm{Cl}$, confidence interval.

(adjusted $\beta=-0.121,95 \% \mathrm{CI}=-0.202 \sim-0.039)$ remained similar as those in crude models, and the association between social service support (adjusted $\beta=-0.018,95 \%$ $\mathrm{CI}=-0.083 \sim 0.047)$ and frailty remained non-significant. However, the protective effect of social security on frailty failed to demonstrate significance in the adjusted model (adjusted $\beta=-0.107,95 \% \mathrm{CI}=-0.220 \sim 0.007$ ).

\section{Mediating Effect of Frailty on the Association Between Social Support and Mortality}

The mediation effect of frailty on the association between social support (and its three components) and mortality is illustrated in Table 4. Results showed that frailty was consistently associated with increased odds of mortality, after controlling for social support (or its components) and other covariates (all $p<0.05$ ). After additionally introducing frailty into the adjusted models, a higher level in social support $(\mathrm{AOR}=0.955,95 \% \mathrm{CI}=0.925 \sim 0.987)$, family support ( $\mathrm{AOR}=0.938,95 \% \mathrm{CI}=0.883 \sim 0.996$ ) or social security availability $(\mathrm{AOR}=0.867,95 \% \mathrm{CI}=$
0.799 0.940) remained significantly associated with reduced mortality risk.

Results from mediation analysis indicated that after controlling for all covariates, the overall social support and the family support source showed significant relative indirect effects on mortality risk through frailty ( $95 \%$ biascorrected bootstrap CIs for their corresponding relative indirect effects did not overlap zero), and the relative proportions of mediation for social support and family support were $17.1 \%$ and $20.5 \%$, respectively. However, the mediating effect of frailty on the relationship of social service or social security with mortality was nonsignificant.

\section{Discussion}

The present study investigated the associations among social support, frailty and mortality in a large-scale nationwide sample of Chinese older adults over a 10-year duration, and one of its major strengths was focusing particularly on the distinct impact from specific sources of social support. To our best knowledge, this study was also the first in China to examine the mediating role of 
Table 4 Mediating Effect of Frailty on the Association Between Social Support and Mortality at Follow-Up in II,934 Older Adults

\begin{tabular}{|c|c|c|c|c|}
\hline \multirow[t]{2}{*}{ Variables } & \multicolumn{2}{|c|}{ Mortality (Dependent Variable, Y) } & \multicolumn{2}{|c|}{ Mediating Effect ${ }^{\mathbf{b}}$} \\
\hline & $\begin{array}{c}\text { Model } I^{\mathrm{a}}: \mathbf{X} \rightarrow \mathbf{Y} \\
\text { OR }(95 \% \mathrm{CI})\end{array}$ & $\begin{array}{l}\text { Model } 2^{a}: X+M \rightarrow Y, \\
\quad \text { OR }(95 \% \mathrm{Cl})\end{array}$ & $\begin{array}{l}\text { Indirect Effect } \\
\qquad(95 \% \mathrm{Cl})\end{array}$ & $\begin{array}{l}\text { Proportion of } \\
\text { Mediation (\%) }\end{array}$ \\
\hline \multicolumn{5}{|l|}{ Social support (total score) } \\
\hline Social support (Independent variable, $X$ ) & $0.947(0.917,0.977)^{* *}$ & $0.955(0.925,0.987)^{* *}$ & $-0.0093(-0.0178,-0.0019)^{*}$ & $17.1 \%$ \\
\hline Frailty (Mediator, M) & & $1.180(1.158,1.203)^{* * *}$ & & \\
\hline \multicolumn{5}{|l|}{ Social support (components) } \\
\hline Family support (Independent variable, $X$ ) & $0.918(0.865,0.973)^{* *}$ & $0.938(0.883,0.996)^{*}$ & $-0.0162(-0.0313,-0.0024)^{*}$ & $20.5 \%$ \\
\hline Frailty (Mediator, M) & & $1.180(1.158,1.202)^{* * *}$ & & \\
\hline Social service (Independent variable, $X$ ) & $0.988(0.946,1.033)$ & $0.994(0.950,1.040)$ & $-0.0035(-0.0150,0.0078)$ & NA \\
\hline Frailty (Mediator, M) & & I.I8I $(1.159,1.203)^{* * * *}$ & & \\
\hline Social security (Independent variable, X) & $0.869(0.803,0.940)^{* * *}$ & $0.867(0.799,0.940)^{* *}$ & $-0.0136(-0.0325,0.0062)$ & NA \\
\hline Frailty (Mediator, M) & & I.I8I (I.159, I.204)*** & & \\
\hline
\end{tabular}

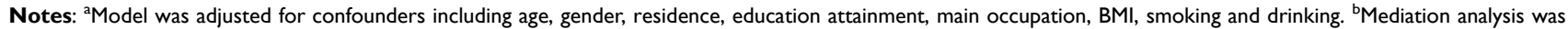
conducted through a bootstrapping procedure with 5000 resamples, through which we assessed the bias-corrected bootstrap confidence intervals (Cl) of indirect effects. NA: Not applicable, where the indirect effect was not statistically significant. ${ }^{*} p<0.05,{ }^{*} p<0.01,{ }^{*} * *_{p}<0.00 \mathrm{I}$.

Abbreviations: OR, odds ratio; $\mathrm{Cl}$, confidence interval.

frailty underlying the pathway from social support absence to mortality, thereby providing evidence for possible mechanisms that could guide the development of tailored public health interventions.

Our study reinforced the evidence of mortality risk in relation to social support, using a cohort of older Chinese residents in the community. According to previous literature, increasing social support level or interventions that included social support exhibited positive associations with reduced mortality in older adults. ${ }^{5-8,33}$ By contrast, there were some other studies reporting inconsistent findings. For example, one study indicated that survival remained unchanged regardless of the level in social support, ${ }^{34}$ and another found that social support was predictive of mortality only in individuals with the highest comorbidity. ${ }^{35}$ Discrepancies of these findings could perhaps be explained by variations in study design, nonconsensus on social support measurement or differences in components of social support intervention, as well as strikingly varied cultural contexts across these studies.

Accumulating evidence has revealed the importance of social support in protecting against frailty among older adults, which is consistent with our finding. ${ }^{21-23,36,37} \mathrm{We}$ postulate the following plausible reasons for the observed association. First, provision of social support to older adults could probably enhance intimacy, comfort and selfcompetence, leaving them less vulnerable to stress and psychological pathology. ${ }^{3,38}$ Second, social relationships could increase availability of instrumental assistance as well as improve access to healthcare professionals and services, which would in turn, protect older persons against deteriorating conditions. ${ }^{39,40}$ Both facts could contribute to reduced frailty. Despite positive findings, there were also contradictory results reporting no evidence of an association between social support and frailty. ${ }^{41,42}$ Exact reason for the inconsistency remained uncertain, and it could be related to the cultural diversities, small sample size or cross-sectional design. In addition to investigation into social support and frailty, our study further demonstrated that frailty was predictive of mortality in older people, which was consistently observed in an abundant number of previous studies. ${ }^{16-20}$ Possible explanation could be that frailty denoted a multidimensional accumulation of health deficits and vulnerability to stressors, which could act as a precursor to functional limitation, falls, hospitalisation, poor quality of life, and eventually mortality. ${ }^{14,15}$

Most previous studies failed to distinguish the differences in distinct sources of social support. Our findings enriched the existing literature by empirically showing that the protective role of social support in reducing mortality and frailty varied by support sources in Chinese older population. Namely, the support from family and social security exhibited profoundly protective influences on mortality while the other source of social service did not demonstrate significant effect. Additionally, support from family denoted a greater effect on frailty than other support sources. Our study emphasized the difference between 
specific sources of social support, of which family-based support showed the most significant effect. A few previous studies in China also concluded similar findings when they investigated other health outcomes. For instance, family support was found as a strongest predictor for improved cognitive function $^{43}$ and reduced depressive symptom ${ }^{11}$ among older adults in studies conducted by Zhu et al and Yin et al. This finding is in line with our expectations, given that Chinese culture differs largely from that of Western countries. ${ }^{11}$ China is traditionally a family-careoriented society, where filial piety and the core pillar of Confucian ethics demonstrates that children have a fundamental obligation to care for their parents. ${ }^{11,12}$ The family support is thus more emotionally close, meaningful, enduring, and dependable compared with other sources of support, thereby contributing to higher health rewards.

Many researchers have suggested that overall longevity may be attributable to a complex combination of physiological, social and environmental factors, ${ }^{2,44}$ while the underlying mechanisms still remain poorly investigated. The present study observed that frailty, as a multidimensional geriatric syndrome, mediated approximately $20 \%$ of the relationship of mortality with social support or family support in Chinese older people. The mediating effect in relation to social service or social security was yet non-significant. Our results provided the first evidence on the significant mediating role that frailty played underlying the pathway from social support and family-based support to mortality. This indicated that lower social support in general or family support could be disruptive to frailty, which consequently contributed to mortality. Our finding accordingly highlights the importance of targeted interventions towards frailty, general social support, and family-based support in particular for the Chinese context, when considering their modifiable or reversible nature at the same time.

Several limitations should be taken into account when interpreting our findings. First, as previously noted, the CLHLS database only allowed us to measure social service and social security based upon the perceived availability of social service or security, which was not exactly the same as received social service or security. Nevertheless, received social support are considered closely related to perceived availability of social support. ${ }^{11}$ Second, the results might be subject to recall bias because this study relied on mortality information reported by family members and other measures via self report. Additional linkage to death registration data and utilization of the objective clinical or laboratory data are encouraged to reconcile such recall bias. Third, although we adjusted for a wide range of potential confounders in analyses, confounding bias could still be present owing to unobserved differences in personal characteristics. Fourth, although the Cox proportional hazards model was necessary for survival analyses, the exact date of death from registry was not available; hence, we used the logistic regression as the appropriate measure for analyses relating to the effect estimation. However, this approach could allow a minor degree of risk overestimation and therefore results should be interpreted with caution.

\section{Conclusions}

An increasing availability in social support is associated with reduced risks for frailty and mortality, and such protective influences are especially manifested in its family support component among Chinese older adults. Frailty functions as a potential mediator underlying the pathway from increased level in overall social support or family-based support to reduced mortality risk. Our study offers insights into understanding a holistic picture of impact factors and possible mechanisms that could contribute to health longevity among the older population, which is essential for helping identify further targets for healthcare planning and promotion. Policymakers or healthcare practitioners should raise awareness about the importance of placing social support (and particularly improving family-based support in Chinese context) as an integral part of geriatric care, as well as recognize the urgency of frailty assessment and intervention to facilitate healthy aging.

\section{Acknowledgments}

The authors gratefully acknowledge the Center for Healthy Aging and Development Studies, Peking University for supporting this CLHLS database. We are also grateful to all participants involved in the CLHLS research.

\section{Funding}

This work was supported by the Natural Science Foundation of China (NSFC 71704192); the Department of Education of China (No. 1125000172); the Fundamental Research Funds for the Central Universities (2242021R41104, 3225002002A1, 2242020R10007); and the Zhishan Youth Scholar Program of Southeast University (2019-2021). The funders had no role in 
study design, data collection and analysis, decision to publish, or preparation of the manuscript.

\section{Disclosure}

The authors declare no conflict of interests.

\section{References}

1. The Lancet. Ageing in China: a ticking bomb. Lancet. 2016;388 (10056):2058.

2. Wang XQ, Chen PJ. Population ageing challenges health care in China. Lancet. 2014;383(9920):870. doi:10.1016/S0140-6736(14) 60443-8

3. Umberson D, Montez JK. Social relationships and health: a flashpoint for health policy. J Health Soc Behav. 2010;51 Suppl(Suppl):S54S66. doi: $10.1177 / 0022146510383501$

4. Lin N, Simeone RS, Ensel WM, Kuo W. Social support, stressful life events, and illness: a model and an empirical test. $J$ Health Soc Behav. 1979;20(2):108-119. doi:10.2307/2136433

5. LaVeist TA, Sellers RM, Brown KA, Nickerson KJ. Extreme social isolation, use of community-based senior support services, and mortality among African American elderly women. Am J Community Psychol. 1997;25(5):721-732. doi:10.1023/A:1024643118894

6. Andrew MK, Mitnitski AB, Rockwood K. Social vulnerability, frailty and mortality in elderly people. PLoS One. 2008;3(5):e2232. doi:10.1371/journal.pone.0002232

7. Armstrong JJ, Andrew MK, Mitnitski A, Launer LJ, White LR, Rockwood K. Social vulnerability and survival across levels of frailty in the Honolulu-Asia Aging Study. Age Ageing. 2015;44(4):709-712. doi:10.1093/ageing/afv016

8. de Brito TP, Nunes DP, Corona LP, et al. Low supply of social support as risk factor for mortality in the older adults. Arch Gerontol Geriatr. 2017;73:77-81. doi:10.1016/j.archger.2017.07.016

9. Hu H, Cao Q, Shi Z, Lin W, Jiang H, Hou Y. Social support and depressive symptom disparity between urban and rural older adults in China. $J$ Affect Disord. 2018;237:104-111. doi:10.1016/j. jad.2018.04.076

10. Zurlo KA, Hu H, Huang CC. The effects of family, community, and public policy on depressive symptoms among elderly Chinese. $J$ Sociol Soc Work. 2014;2:1-23. doi:10.15640/jssw.v2n2a1

11. Yin S, Yang Q, Xiong J, Li T, Zhu X. Social support and the incidence of cognitive impairment among older adults in China: findings from the Chinese Longitudinal Healthy Longevity Survey study. Front Psychiatry. 2020;11:254. doi:10.3389/fpsyt.2020.00254

12. Li C, Jiang S, Zhang X. Intergenerational relationship, family social support, and depression among Chinese elderly: a structural equation modeling analysis. $J$ Affect Disord. 2019;248:73-80. doi:10.1016/j. jad.2019.01.032

13. Liu H, Xiao Q, Cai Y, Li S. The quality of life and mortality risk of elderly people in rural China: the role of family support. Asia Pac $J \quad$ Public Health. 2015;27(2):2232-2245. doi:10.1177/ 1010539512472362

14. Strandberg TE, Pitkala KH. Frailty in elderly people. Lancet. 2007;369(9570):1328-1329. doi:10.1016/S0140-6736(07)60613-8

15. Dent E, Martin FC, Bergman H, Woo J, Romero-Ortuno R, Walston JD. Management of frailty: opportunities, challenges, and future directions. Lancet. 2019;394(10206):1376-1386. doi:10.1016/ S0140-6736(19)31785-4
16. Kojima G, Iliffe S, Walters K. Frailty index as a predictor of mortality: a systematic review and meta-analysis. Age Ageing. 2018;47 (2):193-200. doi:10.1093/ageing/afx162

17. Shamliyan T, Talley KM, Ramakrishnan R, Kane RL. Association of frailty with survival: a systematic literature review. Ageing Res Rev. 2013;12(2):719-736. doi:10.1016/j.arr.2012.03.001

18. Chang SF, Lin PL. Frail phenotype and mortality prediction: a systematic review and meta-analysis of prospective cohort studies. Int $J$ Nurs Stud. 2015;52(8):1362-1374. doi:10.1016/j. ijnurstu.2015.04.005

19. Zhang X, Dou Q, Zhang W, et al. Frailty as a predictor of all-cause mortality among older nursing home residents: a systematic review and meta-analysis. J Am Med Dir Assoc. 2019;20(6):657-663. doi:10.1016/j.jamda.2018.11.018

20. Man C, Xiang S, Fan Y. Frailty for predicting all-cause mortality in elderly acute coronary syndrome patients: a meta-analysis. Ageing Res Rev. 2019;52:1-6. doi:10.1016/j.arr.2019.03.003

21. Buttery AK, Busch MA, Gaertner B, Scheidt-Nave C, Fuchs J. Prevalence and correlates of frailty among older adults: findings from the German health interview and examination survey. $B M C$ Geriatr. 2015;15:22-30. doi:10.1186/s12877-015-0022-3

22. Luger E, Dorner TE, Haider S, Kapan A, Lackinger C, Schindler K. Effects of a home-based and volunteer-administered physical training, nutritional, and social support program on malnutrition and frailty in older persons: a randomized controlled trial. $\mathrm{J} \mathrm{Am} \mathrm{Med}$ Dir Assoc. 2016;17(7):671.e9-.e16. doi:10.1016/j.jamda.2016.04.018

23. Chon D, Lee Y, Kim J, Lee K-E. The association between frequency of social contact and frailty in older people: Korean Frailty and Aging Cohort Study (KFACS). J Korean Med Sci. 2018;33(51): e332. doi:10.3346/jkms.2018.33.e332

24. Zeng Y, Poston DA, Vlosky DA, Gu D. Healthy Longevity in China: Demographic, Socioeconomic, and Psychological Dimensions. Dordrecht, The Netherlands: Springer; 2008.

25. Zeng Y, Vaupel JW, Xiao Z, Zhang C. The healthy longevity survey and the active life expectancy of the oldest old in China. Population. 2001;13(1):95-116.

26. Liu ZY, Wei YZ, Wei LQ, et al. Frailty transitions and types of death in Chinese older adults: a population-based cohort study. Clin Interv Aging. 2018;13:947-956. doi:10.2147/CIA.S157089

27. Mitnitski AB, Mogilner AJ, Rockwood K. Accumulation of deficits as a proxy measure of aging. Scientific World J. 2001;1:323-336. doi:10.1100/tsw.2001.58

28. Gu D, Dupre ME, Sautter J, Zhu H, Liu Y, Yi Z. Frailty and mortality among Chinese at advanced ages. J Gerontol B Psychol Sci Soc Sci. 2009;64(2):279-289. doi:10.1093/geronb/gbn009

29. Bennett S, Song X, Mitnitski A, Rockwood K. A limit to frailty in very old, community-dwelling people: a secondary analysis of the Chinese longitudinal health and longevity study. Age Ageing. 2013;42 (3):372-377. doi:10.1093/ageing/afs180

30. Baron MR, Kenny AD. The moderator-mediator variable distinction in social psychological research: conceptual, strategic, and statistical considerations. J Pers Soc Psycho. 1986;51:1173-1182. doi:10.1037/ 0022-3514.51.6.1173

31. Hayes AF. Introduction to Mediation, Moderation, and Conditional Process Analysis: A Regression-Based Approach. New York, USA: The Guilford Press; 2013.

32. Vanderweele TJ, Vansteelandt S. Odds ratios for mediation analysis for a dichotomous outcome. Am $J$ Epidemiol. 2010;172 (12):1339-1348. doi:10.1093/aje/kwq332

33. Pitman A, Kozhuharova P, Lloyd-Evans B, Renwick KA. The influence of low social support and living alone on premature mortality among aging Canadians. BMC Psychiatry. 2020;111(4):594-605. 
34. Kamiya Y. Does Social engagement predict frailty and mortality in the older population? Applied Demography and Public Health in the 21st Century. USA: Springler; 2016.

35. Mazzella F, Cacciatore F, Galizia G, et al. Social support and long-term mortality in the elderly: role of comorbidity. Arch Gerontol Geriatr. 2010;51(3):323-328. doi:10.1016/j.archger.2010.01.011

36. Lurie I, Myers V, Goldbourt U, Gerber Y. Perceived social support following myocardial infarction and long-term development of frailty. Eur J Prev Cardiol. 2015;22(10):1346-1353. doi:10.1177/ 2047487314544575

37. Woo J, Goggins W, Sham A, Ho SC. Social determinants of frailty. Gerontology. 2005;51(6):402-408. doi:10.1159/000088705

38. Berkman LF, Glass T, Brissette I, Seeman TE. From social integration to health: durkheim in the new millennium. Soc Sci Med. 2000;51(6):843-857. doi:10.1016/S0277-9536(00)00065-4

39. Messeri P, Silverstein M, Litwak E. Choosing optimal support groups: a review and reformulation. J Health Soc Behav. 1993;34 (2):122-137. doi:10.2307/2137239
40. Thoits PA. Mechanisms linking social ties and support to physical and mental health. J Health Soc Behav. 2011;52(2):145-161. doi:10.1177/0022146510395592

41. Gale CR, Syddall HE, Cooper C, Sayer AA, Bergman H, Brunner EJ. Close relationships and risk of frailty: the Hertfordshire Cohort Study. J Am Geriatr Soc. 2012;60(2):390-392. doi:10.1111/j.15325415.2011.03799.x

42. Jürschik $P$, Nunin $C$, Botigué $T$, Escobar MA, Lavedán A, Viladrosa M. Prevalence of frailty and factors associated with frailty in the elderly population of Lleida, Spain: the FRALLE survey. Arch Gerontol Geriatr. 2012;55(3):625-631. doi:10.1016/j. archger.2012.07.002

43. Zhu S, Hu J, Efird JT. Role of social support in cognitive function among elders. J Clin Nurs. 2012;21(15-16):2118-2125. doi:10.1111/ j.1365-2702.2012.04178.x

44. Braveman P, Egerter S, Williams DR. The social determinants of health: coming of age. Annu Rev Public Health. 2011;32(1):381-398. doi:10.1146/annurev-publhealth-031210-101218
Risk Management and Healthcare Policy

\section{Publish your work in this journal}

Risk Management and Healthcare Policy is an international, peerreviewed, open access journal focusing on all aspects of public health, policy, and preventative measures to promote good health and improve morbidity and mortality in the population. The journal welcomes submitted papers covering original research, basic science, clinical \& epidemiological studies, reviews and evaluations, guidelines, expert opinion and commentary, case reports and extended reports. The manuscript management system is completely online and includes a very quick and fair peer-review system, which is all easy to use. Visit http://www.dovepress.com/testimonials.php to read real quotes from published authors. 